\title{
Congruence of Patient Self-Rating of Health with Family Physician Ratings
}

\author{
Nancy C. Elder, MD, MSPH, Ryan Imboff, BS, Jennifer Chubinski, PhD, \\ C. Jeffrey Jacobson, Jr., PhD, Harini Pallerla, MS, Petar Saric, PharmD, MD, \\ Vitaliy Rotenberg, MD, Mary Beth Vonder Meulen, RN, CCRC, \\ Anthony C. Leonard, PhD, Mark Carrozza, MA, and Saundra Regan, PhD
}

Background: A single self-rated health (SRH) question is associated with health outcomes, but agreement between SRH and physician-rated patient health (PRPH) has been poorly studied. We studied patient and physician reasoning for health ratings and the role played by patient lifestyle and objective health measures in the congruence between SRH and PRPH.

Methods: Surveys of established family medicine patients and their physicians, and medical record review at 4 offices. Patients and physicians rated patient health on a 5-point scale and gave reasons for the rating and suggestions for improving health. Patients' and physicians' reasons for ratings and improvement suggestions were coded into taxonomies developed from the data. Bivariate relationships between the variables and the difference between SRH and PRPH were examined and all single predictors of the difference were entered into a multivariable regression model.

Results: Surveys were completed by 506 patients and 33 physicians. SRH and PRPH ratings matched exactly for $38 \%$ of the patient-physician dyads. Variables associated with SRH being lower than PRPH were higher patient body mass index $(P=.01)$, seeing the physician previously $(P=.04)$, older age, $(P<.001)$, and a higher comorbidity score $(P=.001)$. Only $25.7 \%$ of the dyad reasons for health status rating and $24.1 \%$ of needed improvements matched, and these matches were unrelated to SRH/PRPH agreement. Physicians focused on disease in their reasoning for most patients, whereas patients with excellent or very good SRH focused on feeling well.

Conclusions: Patients' and physicians' beliefs about patient health frequently lack agreement, confirming the need for shared decision making with patients. (J Am Board Fam Med 2017;30:196-204.)

Keywords: Decision Making, Health Status, Lifestyle, Medical Records, Motivational Interviewing, Physician-Patient Relations, Surveys and Questionnaires

An individual's response to the question, "In general, how would you rate your overall health?" has intrigued health researchers for decades and is consistently associated with future mortality, morbidity, and health care costs. ${ }^{1-4}$ Investigators have studied the relationship of a number of

This article was externally peer reviewed.

Submitted 1 August 2016; revised 8 November 2016; accepted 14 November 2016.

From the College of Medicine, University of Cincinnati, Cincinnati, OH (RI, PS, VR); the Department of Family and Community Medicine, University of Cincinnati, Cincinnati (NE, HP, MBVM, ACL, SR); Interact for Health, Cincinnati (JC); the Department of Anthropology, University of Cincinnati, Cincinnati, (CJJ); and the American Academy of Family Physicians, Leawood, KS (MC).

Current affiliation: the Department of Health Services Administration, Xavier University, Cincinnati, OH (RI); factors with self-rated health (SRH) and have generally found poorer SRH to be associated with lower socioeconomic or minority status, lower educational attainment, more chronic illnesses, lower health literacy, poorer social support, poorer neighborhood quality, and more

University Hospitals, Cleveland Medical Center/Case Western Reserve University, Cleveland, (PS); Loyola University Medical Center, Chicago, IL (VR).

Funding: Funding was provided by a grant from Interact for Health, Cincinnati, OH, and the United Way of Cincinnati, Cincinnati, $\mathrm{OH}$.

Conflict of interest: none declared.

Corresponding author: Nancy C. Elder, MD, MSPH, Department of Family and Community Medicine, University of Cincinnati, PO Box 670582, Cincinnati, OH 4526570582 (E-mail: Nancy.Elder@uc.edu). 
smoking and binge drinking. ${ }^{5-13}$ In a 2009 review of SRH, Jylha ${ }^{8}$ proposes a conceptual model of SRH that incorporates the state of the human body and the mind, lying at the crossroads of culture and biology. However, relatively little research has examined the relationship of SRH with more clinical indicators of health, including physician ratings of patient health (PRPHs). ${ }^{14-17}$

As early as 1958, researchers concluded that "self-ratings of health measure something different from physician's ratings." ${ }^{18}$ Yet, only a handful of studies have examined congruence between SRH and PRPH, and the collection of data through structured research encounters with an unfamiliar physician limits the potential for understanding the more stable and holistic effects of the relationship between primary care patients and their own physicians. Desalvo and Muntner, ${ }^{14}$ for example, compared PRPHs with participants' SRH following a single examination by a research clinician as part of the National Health and Nutrition Examination Survey and found a $54 \%$ agreement when ratings were grouped (excellent/very good vs good vs fair/ poor). General practitioners in Denmark had a $68 \%$ agreement with patients after a structured health discussion (poor vs moderate vs good vs very good health). ${ }^{15}$ And Mellner and Lundberg ${ }^{17}$ asked physicians to rate a sample of middle-aged women after they performed a structured general health checkup as part of a larger study; the overall agreement between the women's SRH and the PRPH was $22 \%$.

The limited congruence between SRH and PRPH observed in these relatively impersonal and structured patient-physician interactions suggests a misalignment of health frames and raises the question of whether these findings hold for established physician-patient relationships. Calls to incorporate SRH clinically as a potentially "useful and convenient tool" and as a primary care "vital sign" suggest the need to better understand the cognitive bases shaping patterns of SRH/PRPH congruence in clinical practice. To this end, we sought to better understand the congruence of SRH and PRPH among a cohort of family medicine patients in the Cincinnati Area Research and Improvement Group practice-based research network. To assess the alignment of health frames, we also examined respondents' reasons for ratings and beliefs about how health could be improved.

\section{Methods}

\section{Design and Setting}

As part of a larger study exploring SRH in our community, we surveyed patients and their physicians and reviewed and abstracted medical records at 4 offices in the Cincinnati Area Research and Improvement Group practice-based research network. The 4 family medicine offices were a convenience sample chosen to provide varied geography and payer mix. There were 2 suburban and 2 urban offices; 2 offices had $>20 \%$ Medicaid/uninsured patients. Of the 4 offices, 2 were affiliated with an academic health center and 2 were from a regional nonprofit health system (1 of these was a family medicine residency). All offices used an electronic health record. Data were collected from June 1 through September 30, 2013. This study was approved by the University of Cincinnati and the Christ Hospital institutional review boards.

\section{Participants}

Adult patients waiting for a visit with their family physician were approached by research assistants and assessed for inclusion criteria: at least 2 prior visits to the office (not necessarily to today's scheduled physician), age $\geq 18$ years, English speaking, and able to answer questions independently, either verbally or in writing. Each office was visited for multiple half days, both mornings and afternoons. If patients qualified, they were asked to complete a 2-page survey, which took 5 to 10 minutes to complete.

\section{Data Collection}

\section{Patient Survey}

The patient survey was created using a subset of questions from the 2013 Greater Cincinnati Community Health Status Survey (survey development details are available from https://www.interactforhealth.org/ greater-cincinnati-community-health-status-survey); these questions were chosen to assess demographic and patient factors likely to be associated with SRH and of interest regarding policy within the greater Cincinnati community. We pilot tested the survey for readability and comprehension using several patients at nonparticipating practices and revised it minimally before use. The survey began with the SRH question, "In general, how would you rate your health?" Responses included excellent, very good, good, fair, and poor. We then asked, "What would you say is the 
single most important reason you decided to rate your overall health the way you did?" and "What would you say is the single most important thing that you would need to change for you to improve your health?" Following these questions, a number of patient characteristics and health related behaviors were queried (Table 1).

\section{Physician Survey}

At the end of each half-day of data collection, physicians were asked, for each patient who completed a survey, "In general, how would you rate your patient's health?" The then were asked the same 2 open-ended questions (about the patient) as in the patient survey.

\section{Medical Record Review and Abstraction}

To assess any potential role of objective indicators of health in SRH/PRPH congruence, we reviewed charts for the total number of previous visits and any previous visits with today's physician, as well as body mass index (BMI) and insurance (Table 1). In addition, all chronic problems and current medications were documented. The reviews and abstractions were performed by a clinical research nurse (MBVM), a pharmacist (PS), and a physician (NCE). Approximately $25 \%$ of the charts were reviewed by 2 people to ensure consistency. After reviewing the literature for morbidity indices appropriate for outpatient primary care, ${ }^{20-25}$ we chose the following variables, which have been validated in outpatient settings and could be calcu- lated from the available medical record abstraction data.

\section{Health-Related Quality of Life Comorbidity}

Index. The Health-Related Quality of Life Comorbidity Index (HRQL-CI) ${ }^{24}$ was derived from the medical condition components of the Medical Expenditure Panel Survey and the 12-item Short Form health survey. We determined the total HRQL-CI scores for our patients by assigning appropriate weights to documented chronic problems.

$\boldsymbol{R} \boldsymbol{x}$-Risk-V. The Rx-Risk- $\mathrm{V}^{23}$ is a pharmacy-based measure of comorbidity derived from pharmacy refill data from a large Veterans Affairs system that adapted and updated the original Rx-Risk for an outpatient population. We determined the $\mathrm{Rx}$ Risk-V score for our patients by assigning appropriate values to each medication.

\section{Analysis Quantitative Survey Data}

Bivariate analyses explored the relationships between all the collected variables with the congruence of SRH with PRPH. Multivariable models of the difference between SRH and PRPH began with all individual factors listed in Table 1, then underwent backward selection of the weakest predictor until all remaining predictors, adjusted for the other remaining predictors, had $P$ values $<.05$. In identifying the remaining predictors, we found that the 2 measures of comorbidity (Rx-Risk-V and the HRQL-CI) were highly correlated, with a Pearson correlation of 0.64.

Table 1. Variables Tested for Association with Congruence Between Physician and Patient Ratings, Reasons, and Improvements

\begin{tabular}{|c|c|}
\hline Source & Variable \\
\hline \multirow[t]{7}{*}{ Patient survey } & Demographics (age, sex, race, ethnicity, marital status) \\
\hline & Educational attainment \\
\hline & Average weekly exercise ( $<3$ vs $\geq 3$ days) \\
\hline & Average daily fruits/vegetables ( $<5$ vs $\geq 5$ servings) \\
\hline & $\begin{array}{l}\text { Risky alcohol use ( } 5 \text { drinks at } 1 \text { time for men or } 4 \text { drinks at } 1 \text { time for women at least } \\
\text { once in the past month) }\end{array}$ \\
\hline & Current smoker \\
\hline & Household income \\
\hline \multirow[t]{4}{*}{ Medical record review and abstraction } & Body mass index \\
\hline & Seen today's provider previously \\
\hline & Number of visits to the office in the past 12 months \\
\hline & Type of insurance (private vs Medicare vs Medicaid/self-pay) \\
\hline \multirow[t]{2}{*}{ Comorbidity indices } & Health-Related Quality of Life comorbidity index \\
\hline & $\mathrm{Rx}-\mathrm{Risk}-\mathrm{V}$ medication risk index \\
\hline
\end{tabular}


Because of this, we elected to use just 1 comorbidity measure in the model, and chose the HRQL-CI because we thought the concept of disease burden was more clearly captured by this measure. Agreement between individual SRH and PRPH was assessed using simple and weighted $\kappa$ values across all pairs of ratings, without using nesting factors.

Because most physicians rated more than 1 patient, all reported $P$ values, including those for individual predictors, were derived from mixed models in which physician was a random factor, with an assumed variance component covariance structure. All analyses were conducted using SPSS statistical software (linear mixed models), and the study $\alpha$ was a 2-tailed $P=.05$, unadjusted for multiple tests.

\section{Short-Answer Qualitative Coding}

The short answers given by patients and physicians concerning the "single most important reason" for rating as they did and "single most important thing to change for improvement" were placed into an Excel database. Two analysts (NCE, RI) read the responses and coded each reason and improvement into a taxonomy that was developed from the data themselves. ${ }^{26}$ As new categories occurred, they were added to the taxonomy.

The taxonomy had 3 levels: level 1 comprised 4 main categories, and the second level had specific areas within each category. For example:

\section{- Level 1. Medical concerns}

- Level 2. Number of illnesses, severity, pain, medications, physician visits, mental health

- Level 1. Life and lifestyle

- Level 2. Weight, diet, exercise, age, fatigue, stress, smoking, sleep, social support

- Level 1. Overall health and appearance

- Level 2. Appearance, general health, "how I feel," other general comments on health

\section{- Level 1. Miscellaneous}

- Level 2. Nothing, doing everything I can, "do not know," health care system changes (eg, get insurance), life status changes (eg, get a divorce)

The third level was different for reasons or for improvements. For example, under severity of illness, there were options for "mild," "moderate," and "severe" illness for reasons and "get better control of disease" for improvements needed.
After the short answers had been coded once, they were coded a second time by both analysts using the final taxonomy. Through ongoing discussions, agreement was reached on all the coding decisions. We report here our findings at the second level of the taxonomy.

\section{Results}

We approached 661 patients; 150 refused and 511 completed the surveys. Five surveys were incomplete, leaving 506 valid surveys. The largest number of patients were from 2 suburban, university-affiliated practices (229 and 82 patients, respectively), with 155 coming from the nonprofit urban practice and 42 from the urban residency practice. These patients were seen by 32 physicians (including 12 senior family medicine residents). The number of patient participants per physician ranged from 1 to 64 , with a mean of $16 ; 78 \%$ of physicians rated $>3$ patients. Physician and patient demographics can be found in Table 2.

\section{Health Ratings}

Table 3 shows the congruence of SRH with PRPH. Among the ratings, 38\% matched exactly, whereas $48 \%$ of the matches were off by 1 level (eg, excellent PRPH vs very good SRH); $13.6 \%$ of the matches were off by 2 levels and $0.6 \%$ were off by 3 levels. When there was not an exact match, physicians were about as likely to rate higher $(32.8 \%)$ as they were to rate lower $(29.8 \%)$ than the patient. Assigning a score of 1 to 5 for the responses "poor" (1) to "excellent" (5) gave a mean rating of 2.9 for both the SRH and PRPH. However, across all 506 pairs of SRH and PRPH, the simple $\kappa$ value based on exact agreement in the ratings was 0.16 (95\% confidence interval: $0.10-0.21$ ), whereas the weighted $\kappa$ based on the difference between the 2 ratings was $0.32(0.27-0.38)$, suggesting limited agreement.

Only 4 of the initial factors (Table 1) remained in our multivariable model predicting the difference between SRH and PRPH: higher patient BMI $(P=.01)$, the patient having seen the physician previously $(P=.04)$, older age $(P<.001)$, and a higher HRQL-CI score $(P=.001)$ were associated with a lower SRH relative to the PRPH.

\section{Reasons and Improvements}

Although patients and physicians were asked to give the most important reason or improvement, 
Table 2. Patient and Physician Demographics from Participant Surveys

\begin{tabular}{|c|c|}
\hline \multicolumn{2}{|l|}{ Patient demographics $(\mathrm{n}=506)$} \\
\hline Male sex & 31.7 \\
\hline \multicolumn{2}{|l|}{ Race } \\
\hline African American & 30.6 \\
\hline White & 64.4 \\
\hline Asian American and other/mixed & 5.0 \\
\hline Age (years), mean (SD) & $53.0(16.8)$ \\
\hline \multicolumn{2}{|l|}{ Marital status } \\
\hline Married/partnered & 49.1 \\
\hline Widowed/divorced/separated & 31.3 \\
\hline Never married or partnered & 19.6 \\
\hline Hispanic ethnicity & 2.3 \\
\hline \multicolumn{2}{|l|}{ Education } \\
\hline Less than HS & 8.3 \\
\hline HS grad, some college & 54.0 \\
\hline College graduate & 37.7 \\
\hline \multicolumn{2}{|l|}{ Yearly household income $(\$)$} \\
\hline$<30,000$ & 31.4 \\
\hline $30,000-70,000$ & 36.2 \\
\hline$>70,000$ & 32.4 \\
\hline \multicolumn{2}{|l|}{ Insurance } \\
\hline Private & 62.4 \\
\hline Medicaid/self-pay & 9.7 \\
\hline Medicare & 27.9 \\
\hline \multicolumn{2}{|l|}{ Physician demographics $(\mathrm{n}=32)$} \\
\hline Male sex & 45.5 \\
\hline \multicolumn{2}{|l|}{ Race } \\
\hline White & 72.7 \\
\hline African American & 15.2 \\
\hline Asian American and other/mixed & 12.1 \\
\hline \multicolumn{2}{|l|}{ Age (years) } \\
\hline $25-30$ & 28.1 \\
\hline $31-40$ & 34.4 \\
\hline $41-50$ & 15.6 \\
\hline $51-60$ & 21.9 \\
\hline \multicolumn{2}{|l|}{ Years in practice (nonresidents, $\mathrm{n}=20$ ) } \\
\hline $1-10$ & 35.0 \\
\hline $11-20$ & 30.0 \\
\hline $20-35$ & 35.0 \\
\hline
\end{tabular}

Data are percentages unless otherwise indicated.

HS, high school; SD, standard deviation.

many participants gave multiple answers. We report the 10 most common responses for reasons and improvements in Table 4.

\section{Reasons for Rating}

For patient ratings, "number of illnesses" was the most common reason given by those who rated their health good, fair, and poor. Examples include,
"I've been through a lot of illnesses since I was 19," and "I have several chronic conditions." "General health" was the most common reason category for those rating their health excellent or very good. This included answers such as, "Because for the most part I am healthy." Physicians most frequently cited "number and severity of illnesses" for those patients whose health they rated very good, good, fair, and poor. Examples of these responses from physicians include, "has new thrombosis, uncontrolled hypertension" or, for severity, "moderately severe lung disease." However, for those whose health physicians rated excellent, the top reason was "presence of no illness."

\section{Congruence Between Patient and Physician}

Reasons. While the general categories of reasons were similar for patients and physicians, there was poor congruence for individual physician-patient dyads. Only $25.7 \%$ of the patient and physician reasons were matches, either exact (eg, patient and physicians both said "overweight") or with at least 1 reason matching (eg, patient said "do not exercise enough" and physician said "does not exercise, has diabetes"). In $74.3 \%$ of dyads there were no matches at all. If the dyad matched on their SRH and PRPH, there was a nonsignificant trend toward congruence for cited reasons $(29.1 \%$ matched reasons with exact SRH/PRPH; 25.6\% matched reasons with SRH/PRPH different by 1 level; $15.9 \%$ matched reasons with SRH/PRPH different by 2 or 3 levels $[P=.094])$. The only factors associated with better reason congruence between patients and physicians were when patients reported they "do not drink excessively" $(P=.04)$ and "exercise less often" $(P=.04)$, and when their HRQL-CI was high (more chronic diseases) $(P=.02)$.

\section{Improvements Needed for Better Health Ratings}

Table 4 shows that "lifestyle changes"-more exercise, better food choices, and losing weightwere the top 3 improvements listed by patients. While these were mentioned most frequently by those who rated their health excellent, very good, good, or fair, those with poor SRH most commonly listed getting "medical treatments." Physicians also frequently mentioned weight loss and exercise as the improvements needed for better patient health. Exercise was cited most for those patients whose health physicians rated excellent or very good, and weight loss for those patients they rated good or 
Table 3. Congruence of Physician-Rated Patient Health and Patient Self-Rated Health as Rated by Patients Before an Office Visit and by Physicians After the Office Visit

\begin{tabular}{|c|c|c|c|c|c|c|}
\hline & \multicolumn{5}{|c|}{ Physician-Rated Patient Health } & \multirow[b]{2}{*}{ Total } \\
\hline & Excellent & Very Good & Good & Fair & Poor & \\
\hline \multicolumn{7}{|c|}{ Patient Self-Rated Health } \\
\hline Excellent & $10(2)$ & $17(3)$ & $9(2)$ & $3(0.6)$ & $0(0)$ & $39(8)$ \\
\hline Very good & $34(7)$ & $46(9)$ & $31(6)$ & $14(3)$ & $0(0)$ & $125(25)$ \\
\hline Good & $18(4)$ & $52(10)$ & $78(15)$ & $53(10)$ & $12(2)$ & $213(42)$ \\
\hline Fair & $0(0)$ & $12(2)$ & $36(7)$ & $48(9)$ & $12(2)$ & $108(21)$ \\
\hline Poor & $0(0)$ & $0(0)$ & $4(0.8)$ & $9(2)$ & $8(2)$ & $21(4)$ \\
\hline Total & $62(12)$ & $127(25)$ & $158(31)$ & $127(25)$ & $32(6)$ & $506(100)$ \\
\hline
\end{tabular}

Percentages are of the total number of physician-rated patient health/patient self-rated health dyads $(\mathrm{n}=506)$.

fair. Getting needed treatments was also the most frequent improvement for those whose health physicians rated poor.

Congruence Between Patient and Physician Improvements. Again, while the improvement categories were similar for patients and physicians, individual dyads had poor congruence. Only $24.1 \%$ of the patient-physician dyads matched improvements. There were no significant differences in congruence based on how well the physician and patient matched on their health ratings, nor on whether the physician and patient matched on their reasons for ratings. Of all the factors assessed, only having a high BMI was significantly associated with a match between physician-patient dyad improvements $(P=.008)$.

\section{Discussion}

While a handful of studies in the past 20 years have examined the relationship between physician and patient ratings of health, our study advances this understanding by examining this relationship in naturalistic family medicine clinical settings and by exploring respondents' frames of reference by comparing patients' and physicians' reported reasons for their ratings and associated trajectories for improvement. Our study is also the first to assess the impact of objective, ambulatory care-appropriate measures of health on of SRH/PRPH congruence.

Measuring "objective" health in family medicine is evolving. Previous research on the relationship of SRH to "objective" measures has used the Charlson Comorbidity Index, ${ }^{16}$ disease counts and types, ${ }^{27}$ self-reported diseases, ${ }^{28-30}$ and structured physical examinations and interviews. ${ }^{31} \mathrm{~A}$ recent review of measures of morbidity burden in family medicine concluded that evidence about the reliability of most existing measures in a primary care setting is limited, as most were developed from hospitalized and specialist secondary care settings. ${ }^{22}$ For this reason, we selected 2 newer measures, the HRQL-CI and the Rx-Risk-V, which were developed in community and outpatient populations and were validated for measuring quality of life and mortality. ${ }^{23,24}$ We found that these 2 measures were highly correlated with each other, indicating that they both measure morbidity burden.

When SRH/PRPH congruence was modeled around objective measures, higher patient BMI, older age, and a higher HRQL-CI score (more medical problems) were associated with SHR being lower than PRPH. This finding is consistent with a recent study by DeSalvo and Munter ${ }^{14}$ in which patients with lower SRH, compared with PRPH, had significantly higher BMIs and poorer laboratory findings; however, age was not consistently associated. These types of findings may be partially explained by patients, like those in our study, who focus primarily on medical problems when they rated their health fair or poor. DeSalvo and Munter also found an increased mortality for those with lower SRH compared with PRPH, whereas Hong et $\mathrm{al}^{16}$ found better health outcomes for those patients who rated themselves higher than objective measures would suggest. The conceptual model of SRH put forward Jylha ${ }^{8}$ posits that individuals rate themselves via social and biological pathways mediating information into consciousness, and thus decision making. Further research could help clarify whether there are ways to create protective health effects by intervening in the individual health rating process. 
Table 4. Ten Most Frequently Cited Reasons for Rating Self or the Patient's Health and the 10 Most Frequently Given Improvements Needed to Improve Self or the Patient's Health

\begin{tabular}{|c|c|c|c|c|c|}
\hline \multirow[b]{2}{*}{$\begin{array}{l}\text { Reason for Rating } \\
\text { Patient Health }\end{array}$} & \multirow[b]{2}{*}{$\begin{array}{c}\text { Health } \\
\text { Improvement }\end{array}$} & \multicolumn{2}{|c|}{ Reasons Given } & \multicolumn{2}{|c|}{ Improvements Needed } \\
\hline & & $\begin{array}{c}\text { Patient } \\
\text { Responses } \\
(\mathrm{n}=699)\end{array}$ & $\begin{array}{l}\text { Physician Responses } \\
\qquad(\mathrm{n}=658)\end{array}$ & $\begin{array}{l}\text { Patient Responses } \\
\quad(\mathrm{n}=611)\end{array}$ & $\begin{array}{l}\text { Physician Responses } \\
\qquad(\mathrm{n}=554)\end{array}$ \\
\hline Number of illnesses & - & $122(17 \%)$ & $163(25 \%)$ & & \\
\hline General health & - & $102(15 \%)$ & $24(4 \%)$ & & \\
\hline Exercise & Need to exercise & $63(9 \%)$ & $25(4 \%)$ & $143(23 \%)$ & $100(18 \%)$ \\
\hline Obesity & Lose weight & $58(8 \%)$ & $69(10 \%)$ & $98(16 \%)$ & $105(19 \%)$ \\
\hline Severity of illness & $\begin{array}{l}\text { Improve disease or } \\
\text { get better }\end{array}$ & $52(7 \%)$ & $119(18 \%)$ & $28(5 \%)$ & $23(4 \%)$ \\
\hline $\begin{array}{l}\text { Diet or poor food } \\
\text { choices }\end{array}$ & $\begin{array}{l}\text { Make better food } \\
\text { choices }\end{array}$ & $39(6 \%)$ & & $131(21 \%)$ & $56(10 \%)$ \\
\hline $\begin{array}{l}\text { Presence of no } \\
\text { disease }\end{array}$ & - & $29(4 \%)$ & $35(5 \%)$ & & \\
\hline $\begin{array}{l}\text { General response that } \\
\text { it is "how I feel" }\end{array}$ & - & $26(3 \%)$ & & & \\
\hline Age & - & $20(3 \%)$ & $24(4 \%)$ & & \\
\hline Miscellaneous & - & $20(3 \%)$ & & $48(8 \%)$ & $64(12 \%)$ \\
\hline $\begin{array}{l}\text { Healthy habits and } \\
\text { self-care }\end{array}$ & $\begin{array}{l}\text { Better health habits } \\
\text { in general }\end{array}$ & & $37(6 \%)$ & $10(2 \%)$ & \\
\hline $\begin{array}{l}\text { Mental health } \\
\text { problems }\end{array}$ & $\begin{array}{l}\text { Get mental health } \\
\text { care }\end{array}$ & & $25(4 \%)$ & & $18(3 \%)$ \\
\hline \multirow[t]{6}{*}{ Tobacco use } & Stop smoking & & $21(3 \%)$ & $35(6 \%)$ & $41(7 \%)$ \\
\hline & $\begin{array}{l}\text { Get needed } \\
\text { treatments }\end{array}$ & & & $16(3 \%)$ & $37(7 \%)$ \\
\hline & Decrease stress & & & $15(2 \%)$ & \\
\hline & Get better sleep & & & $14(2 \%)$ & \\
\hline & $\begin{array}{l}\text { Get better } \\
\text { medication } \\
\text { adherence }\end{array}$ & & & & $30(5 \%)$ \\
\hline & $\begin{array}{l}\text { Keep doctor } \\
\text { appointments } \\
\text { and follow advice }\end{array}$ & & & & $26(5 \%)$ \\
\hline
\end{tabular}

Patients and physicians could give more than 1 response. Miscellaneous reasons for ratings included larger health care issues (insurance, incurable diseases) and life status (lack of money), whereas miscellaneous improvements needed included changes in these categories (change the health care system, win the lottery) and statements about already doing everything or needing to do everything.

Understanding the correlates and determinants of patient SRH has been the focus of many studies and models, but few studies have probed the cognitive bases or frames of responses (ie, have asked people why they rated as they did), and none have asked both patients and their physicians why they rated as they $\operatorname{did} .^{5,6,8,11,17} \mathrm{We}$ found that many of the same reasons were given by both patient and physician groups. However, there was little congruence when individual patient-physician dyads were studied, with just over one quarter of the pairs matching on reasons. Even those dyads with matched SRH/PRPH ratings were not statistically more likely to match reasons. All this corroborates the idea that patients and doctors use different evaluative frames when rating health. A closer look at the reasons given by patients and physicians helps explain that discordance. We found that physicians tended to focus on disease in their reasoning for all patients, whereas those patients with excellent and very good SRH focused on feeling well. In medicine, wellness is often considered the absence or prevention of disease, but other concepts within wellness, such as happiness and contentment, may be equally or more important to patients. While a growing body of research studies happiness and wellness, ${ }^{32,33}$ and limited research has found a correlation between SRH and happiness, ${ }^{34}$ future research is needed to better understand patients' beliefs about wellness related to health ratings.

Primary care physicians spend a significant portion of their time assisting patients with behavior 
change. Motivational interviewing techniques encourage physicians to ask open-ended questions to elicit what is important to patients ${ }^{35}$; however, physicians may skip this step and simply work with patients to change behaviors physicians think are important. Our findings show that physicians and patients are only in agreement about the "most important thing to change" about $24 \%$ of the time. Not taking the time to elicit patients' opinions may prove counterproductive for this important component of primary care practice.

This study has several limitations. Participants were from only 4 family medicine practices, which included some senior residents, in 1 geographic region; those in other regions or other primary care specialties may respond differently. Non-English speakers were excluded for convenience, and they, too, may give different responses. As an initial study looking at congruence between patients and physicians, however, its findings have relevance and set the stage for future research in other populations and locations. In addition, we kept the patient survey short so it could be completed while waiting for an appointment, and not all potential factors for health rating were included; however, many factors known to be important from the literature were included.

\section{Conclusions}

Previous research has shown that SRH is associated with future mortality, morbidity, and health care costs. ${ }^{1-3}$ This study adds to our understanding of patients' and physicians' reasons for how they rate patient health and their beliefs about improving patient health ratings. We believe this is the first study to explore the congruence of SRH and PRPH based on the patients' and physicians' routine interactions. Exploration of individual physician-patient dyads provides evidence that physicians cannot assume they know how patients perceive their own health, nor what is most important to patients to improve their health. Open and ongoing communication between physicians and patients, as recommended in motivational interviewing, remains key to patient-centered primary care.

To see this article online, please go to: http://jabfm.org/content/ 30/2/196.full.

\section{References}

1. Banerjee D, Perry M, Tran D, Arafat R. Self-reported health, functional status and chronic disease in community dwelling older adults: untangling the role of demographics. J Community Health 2010;35: 135-41.

2. Bierman AS, Bubolz TA, Fisher ES, Wasson JH. How well does a single question about health predict the financial health of medicare managed care plans? Eff Clin Pract 1999;2:56-62.

3. Bosworth HB, Siegler IC, Brummett BH, et al. The relationship between self-rated health and health status among coronary artery patients. J Aging Health 1999;11:565-84.

4. Idler EL, Benyamini Y. Self-rated health and mortality: a review of twenty-seven community studies. J Health Soc Behav 1997;38:21-37.

5. Murata C, Kondo T, Tamakoshi K, Yatsuya H, Toyoshima H. Determinants of self-rated health: could health status explain the association between self-rated health and mortality? Arch Gerontol Geriatr 2006;43:369-80.

6. Unden AL, Elofsson S. Do different factors explain self-rated health in men and women? Gend Med 2006;3:295-308.

7. Rohrer JE, Young R, Sicola V, Houston M. Overall self-rated health: a new quality indicator for primary care. J Eval Clin Pract 2007;13:150-3.

8. Jylha M. What is self-rated health and why does it predict mortality? Towards a unified conceptual model. Soc Sci Med 2009;69:307-16.

9. Sirola J, Tuppurainen M, Rikkonen T, Honkanen R, Koivumaa-Honkanen H, Kröger H. Correlates and predictors of self-rated health and ambulatory status among elderly women - cross-sectional and 10 years population-based cohort study. Maturitas 2010;65: 244-52.

10. Smith PM, Glazier RH, Sibley LM. The predictors of self-rated health and the relationship between self-rated health and health service needs are similar across socioeconomic groups in Canada. J Clin Epidemiol 2010;63:412-21.

11. Layes A, Asada Y, Kepart G. Whiners and deniers what does self-rated health measure? Soc Sci Med 2012;75:1-9.

12. Mavaddat N, Valderas JM, van der Linde R, Khaw KT, Kinmonth AL. Association of self-rated health with multimorbidity, chronic disease and psychosocial factors in a large middle-aged and older cohort from general practice: a cross-sectional study. BMC Fam Pract 2014;15:185.

13. Brunner RL. Understanding gender factors affecting self-rated health. Gend Med 2006;3:292-4.

14. Desalvo KB, Muntner P. Discordance between physician and patient self-rated health and all-cause mortality. Ochsner J 2011;11:232-40. 
15. Geest TA, Engberg M, Lauritzen T. Discordance between self-evaluated health and doctor-evaluated health in relation to general health promotion. Scand J Prim Health Care 2004;22:146-51.

16. Hong TB, Oddone EZ, Dudley TK, Bosworth HB. Subjective and objective evaluations of health among middle-aged and older veterans with hypertension. J Aging Health 2005;17:592-608.

17. Mellner C, Lundberg U. Self- and physician-rated general health in relation to symptoms and diseases among women. Psychol Health Med 2003;8:123-34.

18. Suchman EA, Streib GF, Phillips BS. An analysis of the validity of health questionnaires. Soc Forces 1958;36:223-32.

19. Meurer LN, Layde PM, Guse CE. Self-rated health status: a new vital sign for primary care? WMJ 2001; 100:35-9.

20. Charlson ME, Charlson RE, Peterson JC, Marinopoulos SS, Briggs WM, Hollenberg JP. The Charlson comorbidity index is adapted to predict costs of chronic disease in primary care patients. J Clin Epidemiol 2008;61:1234-40.

21. de Groot V, Beckerman H, Lankhorst GJ, Bouter LM. How to measure comorbidity: a critical review of available methods. J Clin Epidemiol 2003;56: 221-9.

22. Huntley AL, Johnson R, Purdy S, Valderas JM, Salisbury C. Measures of multimorbidity and morbidity burden for use in primary care and community settings: a systematic review and guide. Ann Fam Med 2012;10:134-41.

23. Johnson ML, El-Serag HB, Tran TT, Hartman C, Richardson P, Abraham NS. Adapting the $\mathrm{Rx}^{-}$ Risk- $\mathrm{V}$ for mortality prediction in outpatient populations. Med Care 2006;44:793-7.

24. Mukherjee B, Ou HT, Wang F, Erickson SR. A new comorbidity index: the health-related quality of life comorbidity index. J Clin Epidemiol 2011;64:309-19.
25. Putnam KG, Buist DS, Fishman P, et al. Chronic disease score as a predictor of hospitalization. Epidemiology 2002;13:340-6.

26. Miller W, Crabtree BF. Qualitative analysis: how to begin making sense. Fam Pract Res J 1994;14:289-97.

27. Kivinen P, Halonen P, Eronen M, Nissinen A. Selfrated health, physician-rated health and associated factors among elderly men: the Finnish cohorts of the Seven Countries Study. Age Ageing 1998;27: 41-7.

28. Hong TB, Zarit SH, Malmberg B. The role of health congruence in functional status and depression. J Gerontol B Psychol Sci Soc Sci 2004;59: P151-7.

29. Ruthig JC, Chipperfield JG. Health incongruence in later life: implications for subsequent well-being and health care. Health Psychol 2007;26:753-61.

30. Van Doorn C. A qualitative approach to studying health optimism, realism and pessimism. Res Aging 1999;21:440-57.

31. Giltay EJ, Vollaard AM, Kromhout D. Self-rated health and physician-rated health as independent predictors of mortality in elderly men. Age Ageing 2012;41:165-71.

32. Delamothe T. Happiness. BMJ 2005;331:1489-90.

33. The science behind the smile. Harvard Business Review, January/February 2012.

34. Subramanian SV, Kim D, Kawachi I. Covariation in the socioeconomic determinants of self rated health and happiness: a multivariate multilevel analysis of individuals and communities in the USA. J Epidemiol Community Health 2005;59:664-9.

35. Miller WR, Rollnick S. Motivational interviewing: helping people change. 3rd edition. New York: Guilford Press; 2012. 